\title{
O trabalho remoto de enfermeiros docentes em tempos de pandemia $^{a}$
}

\author{
Remote work of nurse-professors in pandemic times \\ Trabajo remoto de enfermeros docentes en tiempos de pandemia
}

\begin{abstract}
Anna Raquel Lima Araújo ${ }^{1}$ Larisse Marques Costa Sousa ${ }^{1}$ Rita Beatriz de Sousa Carvalho ${ }^{1}$ Adélia Dalva da Silva Oliveira ${ }^{1}$ Fernanda Cláudia Miranda Amorim ${ }^{1}$ (1) Kayo Henrique Jardel Feitosa Sousa ${ }^{2}$ (c) Regina Célia Gollner Zeitoune ${ }^{2}$ (1) Carolinne Kilcia Carvalho Sena Damasceno ${ }^{1}$ (it)

1. Centro Universitário Uninovafapi. Teresina, $\mathrm{PI}$, Brasil.

2. Universidade Federal do Rio de Janeiro, Escola de Enfermagem Anna Nery. Rio de Janeiro, RJ, Brasil.
\end{abstract}

\section{Resumo}

Objetivo: analisar, na percepção de enfermeiros docentes, os efeitos do ensino remoto decorrente da pandemia de Covid-19 na sua vida. Método: estudo descritivo e qualitativo, realizado em um Centro Universitário de Teresina-PI, em outubro de 2020. Participaram da pesquisa 13 enfermeiros docentes. A coleta de dados ocorreu mediante entrevistas individuais, guiadas por um roteiro semiestruturado. Posteriormente, procedeu-se à análise temática de conteúdo. Resultados: os participantes relataram que o ensino remoto gerou mudanças na rotina, com a necessidade de adequação das aulas para o ambiente virtual $e$ rearranjos domésticos. Esses aspectos foram maximizados pela falta de domínio sobre as ferramentas digitais, o que aumentou as demandas de trabalho. Algumas vezes eles sentiram-se angustiados, tristes, culpados e sozinhos devido aos entraves para estabelecer relações com os alunos. A sobrecarga laboral contribuiu para o adoecimento físico e emocional dos enfermeiros docentes, que referiram estresse, cansaço, dificuldades para dormir, problemas de circulação sanguínea e de alimentação e danos visuais. Considerações finais e implicações para a prática: o ensino remoto tem produzido demandas elevadas, que exacerbam situações de risco para adoecimento dos participantes; portanto, estratégias devem ser pensadas com foco na ressignificação do trabalho docente, uma temática ainda incipiente nas investigações.

Palavras-chave: Docentes de Enfermagem; Educação em Enfermagem; Infecções por Coronavírus; Saúde do Trabalhador; Tecnologia Educacional.

\section{Abstract}

Objective: from the perspective of nurse-professors, to analyze the effects of remote teaching because of the COVID-19 pandemic on their lives. Method: a descriptive and qualitative study, conducted in October 2020 at a University Center in Teresina-PI. The research participants were 13 nurse-professors. Data collection took place by means of individual interviews, guided by a semi-structured script. Subsequently, content thematic analysis was performed Results: the participants reported that remote teaching generated changes in the routine, with the need to adapt the class to the virtual environment and to implement home rearrangements. These aspects were maximized by lack of mastery in terms of the digital tools, which increased the work demands. Sometimes they felt anguished, sad, guilty, and alone due to the obstacles to establish good relationships with the students. Work overload contributed to physical and emotional illness in the nurse-professors, who reported stress, tiredness, difficulty sleeping blood circulation and eating problems, and visual impairment. Final considerations and implications for the practice: remote teaching has generated high demands, which exacerbate risk situations for the participants' illness; therefore, strategies must be thought out focusing on the re-signification of the teaching work, a theme that is still incipient in research studies.

Keywords: Faculty, Nursing; Education, Nursing; Coronavirus Infections; Occupational Health; Educational Technology.

\section{Resumen}

Objetivo: según la percepción de enfermeros docentes, analizar los efectos de la enseñanza remota como consecuencia de la pandemia de Covid-19 en sus vidas. Método: estudio descriptivo y cualitativo realizado en un Centro Universitario de Teresina-P en octubre de 2020. Los participantes fueron 13 enfermeros docentes. La recolección de datos tuvo lugar por medio de entrevistas individuales, guiadas por un guion semiestructurado. Posteriormente, se procedió a realizar el análisis temático de contenido. Resultados: los participantes manifestaron que la enseñanza remota generó cambios en la rutina, con la consecuente necesidad de adaptar las clases al entorno virtual y de implementar modificaciones domésticas. Estos aspectos se vieron maximizados por la falta de dominio de las herramientas digitales, lo que aumentó la cantidad de demandas laborales. En ocasiones se sintieron angustiados, tristes, con culpa y solos debido a los inconvenientes para establecer vínculos con los alumnos. La sobrecarga laboral contribuyó al malestar físico y emocional de los enfermeros docentes, que manifestaron estrés, cansancio, dificultades para dormir, problemas de circulación sanguínea y de alimentación y daños en la vista. Consideraciones finales e implicancias para la práctica: la enseñanza remota ha generado grandes demandas, que intensifican situaciones de riesgo para el malestar de los participantes; por lo tanto, deben pensarse estrategias enfocadas en la resignificación del trabajo docente, una temática que todavía es incipiente en los estudios de investigación.

Palabras clave: Docentes de Enfermería; Educación en Enfermería; Infecciones por Coronavirus; Salud Laboral; Tecnología Educacional. 


\section{INTRODUÇÃO}

O severe acute respiratory syndrome coronavirus 2 (SarsCoV-2), causador da Coronavirus Disease 2019 (Covid-19), foi identificado, no final de 2019, na cidade de Wuhan, China. O grande trânsito de pessoas entre países/territórios, decorrente do processo de globalização, associado à rápida disseminação e alta transmissibilidade do vírus, levou, em janeiro de 2020, a Organização Mundial da Saúde (OMS) a declarar a doença uma emergência de saúde pública de interesse internacional. Em março do mesmo ano, o vírus já havia sido detectado em 215 países/territórios, com altas taxas de mortalidade em todo o mundo e dificuldades dos serviços de saúde em atender à demanda, elevando a doença ao status de pandemia ${ }^{1}$.

Poucas informações existiam sobre o vírus e suas formas de manifestação; no entanto, a transmissão pelo ar foi logo relatada. Ao expirar, as pessoas infectadas liberam pequenas partículas respiratórias com o vírus, que podem ser inaladas imediatamente, se a distância inferior a um metro. Inclusive, após a saída da pessoa infectada do ambiente, as partículas ainda ficam dispersas no ar por horas, e as pessoas que se encontram a uma distância superior a dois metros da fonte original podem inalar quantidades de vírus suficientes para causar infecção². Isso significa que há a possibilidade de transmissão da Covid-19 em longas distâncias, inclusive pelo contato com superfícies e objetos contaminados ${ }^{2,3}$.

Nos primeiros meses de pandemia, a inexistência de vacinas e medicamentos específicos para o tratamento da Covid-19 levou os estados a recomendarem a adoção de medidas não farmacológicas visando mitigar a transmissão do vírus, como: o uso obrigatório de máscaras de proteção, a higienização das mãos e o distanciamento social. Tais medidas permanecem recomendadas até os dias atuais, mesmo com o advento da vacinação em todo o mundo. Para garantir o distanciamento social entre as pessoas, eventos em massa foram cancelados, fronteiras fechadas, trabalho deslocado ao home office, restrição da circulação de transportes, quarentena para grupos de risco e fechamento de instituições de ensino. ${ }^{4}$ Nas cidades de São Paulo e Rio de Janeiro, observou-se que, após a implantação dessas medidas, a taxa de reprodução do vírus ficou inferior a 1 , mas, devido à flexibilização, os valores aumentaram, oscilando entre 1 e $1,3^{5}$.

As medidas de distanciamento social podem reduzir entre 60 e $70 \%$ as interações sociais quando comparado ao período pré-pandemia ${ }^{6}$; e o fechamento das escolas, em $48,9 \%$ o número de reprodução do vírus. Não obstante, na ausência de qualquer intervenção, a taxa de ataque esperada é de 28,3 a 34,6\% ${ }^{7}$. Estudo estimou, para a Irlanda do Norte, que um bloqueio rigoroso com escolas fechadas reduziu em $35 \%$ a reprodução do vírus, e para o País de Gales, em 44\%. Ainda, identificou que medidas de restrição mais rigorosas são mais eficazes para reduzir as mortes ${ }^{8}$.

Dessarte, a substituição das atividades presenciais em instituições de ensino superior públicas ou privadas, por aulas em meios digitais, foi autorizada pelo Ministério da Educação do
Brasil mediante a Portaria n.ํ 343, de 17 de março de 20209; e as atividades práticas em laboratórios ou estágios, não incluídas entre as passíveis de substituição, segundo a Portaria $n$. ㄴ 345 , de 19 de março de $2020^{10}$. No entanto, a Portaria $n . .544$, de 16 de junho de 2020, que revoga as anteriores, autorizou, em caráter excepcional, que essas atividades, independentemente do tipo, poderiam ocorrer com o auxílio de Tecnologias da Informação e Comunicação (TIC), desde que cada curso respeitasse suas Diretrizes Curriculares (DCN) ${ }^{11}$.

Cabe mencionar que a modalidade de ensino remoto na enfermagem, adotada durante a pandemia de Covid-19, deve ser uma situação temporária. O ensino remoto possui aulas síncronas e assíncronas, respectivamente, em tempo real e gravadas com disponibilização de materiais para o grupo de alunos. Ele se difere do tradicional Ensino a Distância (EaD), uma vez que, neste, as atividades ocorrem de forma, predominantemente, assíncronas, com tutores para acompanhamento ${ }^{12}$, diferente do remoto, que exige, do docente, presença constante em salas de aulas virtuais, nas atividades síncronas, utilizando das plataformas digitais.

As plataformas digitais exigem planejamento diferenciado para que as atividades oportunizem uma aprendizagem ativa, e que sejam efetivas tanto para o aluno quanto para o professor. A interrupção de atividades presenciais acelerou a adoção dessas alternativas de ensino-aprendizagem, mediadas por tecnologias educacionais, com o intuito de possibilitar aos alunos a construção e busca pelo conhecimento, garantindo a continuidade do ano letivo. Porém, muitos desafios têm-se mostrado nesse processo para manutenção e fomento à formação de profissionais qualificados ${ }^{12}$.

Em decorrência da pandemia, os professores precisaram adaptar seu ambiente doméstico e transformá-lo em locais de trabalho, elevando seus gastos financeiros com energia elétrica, internet, manutenção de aparelhos eletrônicos, mobiliários, dentre outros, sem necessariamente haver a compensação pelos empregadores. Essa reestruturação intensificou as demandas e a precarização das condições de trabalho que deflagram danos à saúde do trabalhador ${ }^{13}$.

Dessa forma, parte-se do pressuposto de que a modalidade de ensino remota, adotada em decorrência da Covid-19, tem exercido influência sobre o dia a dia do enfermeiro docente, evidenciando indícios de intensificação do trabalho e agravamento das situações de riscos de adoecimento. A partir dessas considerações, elaborou-se a questão norteadora do estudo: quais as mudanças ocorridas no trabalho docente, percebidas por professores de enfermagem, decorrentes da adoção do ensino remoto durante a pandemia de Covid-19? E como objetivo: analisar, na percepção de enfermeiros docentes, os efeitos do ensino remoto decorrente da pandemia de Covid-19 na sua vida.

\section{MÉTODO}

Trata-se de um estudo descritivo e qualitativo, realizado em um Centro Universitário de natureza privada localizado em Teresina-PI. O curso de bacharelado em enfermagem nessa instituição possui um total de $4.047,4$ horas distribuídas em 
9 períodos letivos, sendo $1.332,4$ horas destinadas às atividades práticas, das quais 800 horas distribuídas nos 2 últimos períodos letivos, para o estágio obrigatório e supervisionado em ambientes hospitalares e em unidades básicas de saúde do município. O corpo docente da instituição era composto por 15 enfermeiros docentes que atuavam na graduação e pós-graduação.

Os participantes do estudo foram os enfermeiros docentes que atuavam nos três segmentos educacionais: ensino, pesquisa e/ou extensão. Adotaram-se como critérios de inclusão: ser docente com formação em enfermagem e comprovar no mínimo dois anos de atuação no setor público e/ou privado. Foram excluídos aqueles que se encontravam em licença das atividades por qualquer motivo no momento da coleta de dados. Utilizou-se processo de amostragem por conveniência, no qual todos foram convidados a participar da pesquisa e, após duas tentativas de obtenção do aceite, 2 dos potenciais participantes que não retornaram foram excluídos, totalizando 13 participantes.

A coleta de dados ocorreu em outubro de 2020, mediante entrevistas individuais na plataforma Zoom Meetings ${ }^{\circledR}$, sob mediação de três autoras do estudo. No dia anterior à realização da entrevista, os participantes receberam informações, por meio de mensagens no aplicativo de conversas, sobre a utilização da plataforma a ser adotada nas entrevistas, agendamento do horário mais adequado e orientações relativas às questões éticas do estudo, realizando-se também a assinatura do Termo de Consentimento Livre e Esclarecido. As entrevistas tiveram duração aproximada de 30 minutos, e foram em número suficiente para se alcançar a saturação teórica, constatada pela recorrência e reincidência dos temas. Os conteúdos das entrevistas tiveram gravação de áudio e vídeo na própria plataforma digital.

Utilizou-se um roteiro semiestruturado com questões para caracterização sociodemográfica dos participantes e as perguntas de entrevista: descreva como está sendo seu dia a dia para desenvolver as atividades de ensino; como você está percebendo os impactos na sua vida com o ensino remoto?; e quais estratégias têm adotado para trabalhar a partir de casa durante a pandemia?

Os dados foram analisados segundo a técnica de análise temática de conteúdo, e seguiram-se as fases: pré-análise, exploração do material e tratamento dos dados e inferência dos resultados. ${ }^{14}$ Assim, as entrevistas, após transcritas, foram submetidas à leitura flutuante, para aproximação dos pesquisadores aos conteúdos verbalizados pelos enfermeiros docentes. Em seguida, a partir de repetidas leituras minuciosas, codificaram-se os núcleos de sentido correspondentes a cada questão por participante, a fim de se identificarem os temas recorrentes nas falas. Esse processo de categorização foi realizado pelas três entrevistadoras, isoladamente, e validado - a posteriori - pelos demais autores.

A clareza dos procedimentos metodológicos, a construção do corpus textual e a descrição densa do material de análise conferiram qualidade à investigação. Esse processo permitiu a identificação das unidades de contexto extraídas das falas dos participantes, que representaram o lócus dos acontecimentos experienciados durante o ensino remoto. A partir do levantamento dessas experiências, foi possível a sumarização das unidades de registro, ou seja, os temas que eram evocados mediante os contextos de fala. Os temas que convergiam em significados foram, então, alocados na mesma categoria temática. Por fim, fizeram-se inferências sobre os dados e discussão dos resultados obtidos com auxílio da literatura disponível sobre o assunto.

Respeitaram-se os preceitos éticos das pesquisas que envolvem seres humanos; o projeto de pesquisa foi aprovado pelo Comitê de Ética em Pesquisa da instituição proponente (Parecer n. 4.290.780, de 21 de setembro de 2020). Para garantir o anonimato dos entrevistados, eles foram denominados Participante, seguido de número correspondente à ordem de inserção na pesquisa.

\section{RESULTADOS}

Participaram da pesquisa 13 enfermeiros docentes, majoritariamente do sexo feminino $(n=12)$, com média de 46,5 (24 - 57) anos de idade e 22 (2 - 32) anos de formação. Em relação à atividade docente, obteve-se média de 16,8 (2-26) anos de experiência. Todos relataram possuir pós-graduação, e terem recebido treinamento para a utilização de TIC durante o ensino remoto decorrente da Covid-19.

Neste estudo, as unidades de registro - temas - remetem a acontecimentos vividos pelos participantes. A partir desses acontecimentos, identificou-se a presença de efeitos do ensino remoto decorrente da Covid-19 em dois grandes contextos: o pessoal e o laboral. Com base no princípio da homogeneidadesegundo o qual cada categoria deve possuir uma única unidade de análise ${ }^{14}$-, considerou-se pertinente a categorização das unidades de registro em quatro categorias empíricas: 1 . 0 trabalho remoto e o "novo" modo de fazer o ensino de enfermagem: necessidades e demandas; 2 . Estratégias no fazer o trabalho docente na forma remota; 3 . O trabalho remoto: prós e contras no trabalho do enfermeiro docente; e 4. Efeitos do trabalho remoto na saúde do enfermeiro docente.

\section{O trabalho remoto e o "novo" modo de fazer o ensino de enfermagem: necessidades e demandas}

O "novo" - ensino remoto - é assustador na percepção dos participantes. Os relatos destacam como principais desafios relacionados ao ensino remoto neste período de pandemia - apesar de já utilizarem TIC nas atividades presenciais -, a adequação das metodologias de ensino para aplicação, por meio de plataformas digitais, e a necessidade de manter o aluno sendo participante ativo nesse processo, conforme se observa nas falas:

Não sabíamos direito como transformar uma aula teórica e prática em aula remota (Participante 3).

No começo, foi um desafio muito grande, o novo me assustou. Confesso que não gosto. [...] os medos do ensino remoto, da tecnologia, do novo (Participante 6). 
Eu não tenho contato visual com os alunos, pois eles ficam com as câmeras desligadas. Alguns alunos também demonstram desinteresse em acessar as aulas (Participante 11).

Tive que [...] refazer aulas para adaptá-las para via remota, rever todas as atividades (Participante 12).

A fim de obter êxito nesse processo, mencionaram a necessidade de qualificação profissional para trabalhar com as plataformas digitais e outras tecnologias educacionais, e adotar metodologias ativas em ambiente virtual, além de conhecer o grupo de alunos com os quais atuaria, como evidenciam as falas:

Para prender a atenção do aluno, a gente precisa de muitas ferramentas: utilizar da metodologia ativa, colocar o aluno como centro desse processo do ensino aprendizado. Fizemos muitos treinamentos, muitos cursos, [e] no grupo a gente recebe material, informes para cursos, aulas e são compartilhadas as experiências dos docentes (Participante 4).

O ensino remoto exige mais domínio da tecnologia, capacitação, mais planejamentos das aulas, busca de materiais; e, no meio de tudo isso, nós ainda temos que conduzir as aflições dos alunos. [...] sempre fazendo o diagnóstico situacional da turma (Participante 11).

\section{Estratégias no fazer o trabalho docente na forma remota}

Para atender às demandas do trabalho remoto, foram necessárias adequações no cotidiano doméstico para a manutenção da rotina pessoal e acadêmica, como evidenciado nas falas:

Eu não deixo estender [as atividades] aos sábados à tarde e aos domingos, porque eu tento preservar meu final de semana, o meu horário de descanso e o horário de convívio com meu marido e filha (Participante 4).

Já tínhamos um escritório [em casa] destinado ao trabalho antes da pandemia, porém, às vezes é confuso; porque é só um quarto destinado a essas atividades, e agora todos da casa precisam estar conectados ao mesmo tempo. Com isso, nossa estratégia tem sido cada um ficar em um quarto para não atrapalhar a atividade do outro, e tem dado certo (Participante 5).

[...] tive que mudar totalmente minha rotina (Participante 12).

\section{0 trabalho remoto: prós e contras no trabalho do enfermeiro docente}

Os participantes referiram a necessidade de algumas mudanças, decorrentes da necessidade de distanciamento social, que consideraram positivas no novo ambiente de trabalho remoto, tais como trabalhar a partir de casa, evitar deslocamentos, acompanhar o crescimento dos filhos e flexibilidade, conforme expresso nas falas:

[...] única coisa que mudou é que eu não estou em sala de aula. Vejo de forma muito positiva; primeiro que eu não preciso sair de casa, eu fico na minha casa (Participante 2).

[...] é bom, [porque] você está em casa no conforto do lar, não tem que se deslocar (Participante 3).

Eu me adaptei e percebi que consegui desenvolver habilidades nesse tempo, melhorando minha adaptação e flexibilidade (Participante 4).

O lado positivo é que estou em casa, não tem o deslocamento, e eu consigo acompanhar o crescimento da minha filha (Participante 6).

Contudo, os entrevistados também experienciaram efeitos negativos a partir do ensino remoto, a saber: sobrecarga de trabalho, mudança na rotina doméstica, ausência de feedback dos alunos e uso da câmera para captação da imagem. Esses aspectos foram acrescidos do fato de eles não possuírem domínio sobre as ferramentas digitais e a adaptação das aulas para o ambiente virtual, evidentes nas falas:

Confesso que hoje estou trabalhando bem mais que antes (Participante 6).

A minha carga horária de trabalho está imensurável, ela triplicou. [...] pela facilidade de conexão, eu sou chamada toda hora para treinamento, para tirar uma dúvida de aluno. [...] essa disponibilidade - de você está em casa e acessar o sistema a qualquer momento e a qualquer hora - faz com que a nossa carga horária de trabalho aumente (Participante 7).

[... ] ainda não tenho domínio das ferramentas [...], muito diferente para vocês [entrevistadoras] que nasceram com a internet, com o computador, com tudo. Parece que o tempo ficou mais curto, demanda muito mais tempo da gente (Participante 8).

O estilo de trabalho remoto, que a gente fica em casa compartilhando com outras obrigações, acaba demandando mais atividades. Então, se pensar no todo já vem uma carga de impacto, de demanda maior. [...] afinal, está numa mistura: ambiente de trabalho, ambiente doméstico e familiar, tudo junto (Participante 10).

\section{Efeitos do trabalho remoto na saúde do enfermeiro docente}

As mudanças na rotina pessoal e laboral dos participantes, durante a pandemia de Covid-19, deflagraram alterações emocionais, como tristeza, angústia, medo, solidão, culpa e estresse, decorrentes de um processo de trabalho exaustivo e repetitivo. As falas a seguir ilustram essas situações: 
Tem sido muito cansativo, estressante e repetitivo. São os três adjetivos que eu coloco, principalmente estressante e cansativo; muito mais que o presencial, o remoto está pior, principalmente mental (Participante 1).

Do ponto de vista emocional, estou mais estressada, e isso traz angústia, isso traz vários conflitos emocionais (Participante 7).

No início foi difícil, porque tudo era novo para mim, e eu tive medo de não conseguir, senti nervosismo (Participante 9).

Sinto falta do contato presencial, pois parece que nós não temos vínculos [...]; às vezes, eu até me sinto só nas salas de aula virtual [...]. Eles [os alunos] faltam $e$ me deixam triste, com sentimento de incompetência e de culpa (Participante 11).

Aliado às alterações emocionais, o desgaste físico foi considerado significativo diante das experiências no ensino remoto durante a pandemia de Covid-19. Os participantes mencionaram cansaço, dificuldades para dormir, problemas de circulação sanguínea e de alimentação, e danos visuais. As falas relacionam esses danos à sobrecarga de trabalho e a luminosidade dos aparelhos eletrônicos necessários para que aconteçam as atividades remotas:

Tem sido muito cansativo. Eu tenho ficado fisicamente cansada pela sobrecarga de tarefas que a gente está recebendo via remota (Participante 1).

É mais cansativo [do que o trabalho presencial]. Apesar [...] que é trabalho remoto - você está em casa, você não precisa sair -, é exaustivo. A luz por trás do computador incomoda, me faz sentir fadiga visual (Participante 4).

Estou tendo impactos no ponto de vista físico: problemas de circulação e na coluna, interferência no sono, alimentação e diminuição do apetite (Participante 7).

O ensino remoto foi um grande desafio, impactou muito, inclusive no meu sono (Participante 8).

\section{DISCUSSÃO}

As condições de distanciamento social provocadas pela Covid-19 impuseram, aos professores, a busca por outras formas de organização pedagógica para manutenção da rotina acadêmica dos alunos ${ }^{15}$. Esta pesquisa revelou que a experiência dos enfermeiros docentes em regime de ensino remoto é ambivalente, ora despertando sentimentos positivos, ora sendo potencializador de desgastes físicos e emocionais.

Diante da situação de crise no cenário mundial, instaurada pelas infecções por coronavírus, as instituições de ensino sofreram rápidas modificações na forma de ensinar, tanto na graduação quanto na pós-graduação. Estudo ${ }^{16}$ realizado com alunos universitários de Singapura sugere que a conversão de aulas para o ambiente virtual diminui o potencial de transmissão de doenças, mitigando os danos decorrentes da interrupção das atividades universitárias. Portanto, acredita-se que a adoção do ensino remoto na instituição de pesquisa deste estudo foi uma estratégia viável para fornecer continuidade educacional durante os períodos de alta reprodução do Sars-CoV-2.

Pensar no ensino remoto durante situações de pandemia vem acompanhado de preocupações para uma tomada de decisão assertiva, pautada nas condições de vida de professores e alunos. Estudo ${ }^{17}$ propôs algumas diretrizes que os gestores devem considerar nesse processo de adequação para o ensino remoto: a possibilidade de acesso às plataformas digitais; as habilidades para o manejo das TIC; a disponibilidade de tempo para participar das aulas e estudos independentes; as expectativas relacionadas ao ensino remoto; e o planejamento das atividades e das formas de avaliação de aprendizagem.

A construção de outros espaços/tempos de aula - mais especificamente de salas virtuais - potencializou algumas formas de comunicação mediadas pela tecnologia que não só traz limitações e desafios, mas também proporciona aprendizado. ${ }^{18} \mathrm{O}$ ensino remoto, adotado como medida para dar continuidade ao processo de formação de enfermeiros, está exigindo que enfermeiros docentes recorram aos meios digitais, outrora usados de forma complementar, mas que no momento atual tornaram-se a principal ferramenta para as práticas pedagógicas.

Apesar de dispor de recursos como computadores e dispositivos com acesso à internet, muitos enfermeiros docentes não possuíam habilidades ou familiaridade com as TIC, sendo "forçados" a uma adaptação rápida, que exige grande dedicação e esforço. Os esforços dos professores durante o ensino remoto têm sido aplicados ao preparo e disponibilização de conteúdo, além da adaptação aos meios digitais. Assim, acredita-se que a preocupação com os modos de aprendizagem possa estar sendo deixada para segundo plano, até mesmo devido às dificuldades ocasionadas pelo distanciamento físico ${ }^{19}$.

Além disso, os problemas de conexão e a participação dos alunos nas aulas a distância são somados às dificuldades encontradas pelos professores em se adaptarem aos novos recursos tecnológicos, como gravar videoaulas, ministrar aulas online e utilizar metodologias ativas e $\mathrm{TIC}^{20}$. No caso dos participantes deste estudo, visando auxiliá-los a lidar com o estresse e a ansiedade no exercício de uma função para a qual não estavam preparados, eles receberam capacitação da instituição em prol da continuidade do ensino via plataformas digitais.

Os professores, durante uma atividade remota, precisam ficar atentos à participação efetiva dos alunos, verificar problemas de conectividade, adequar a proposta de aula aos recursos disponíveis na plataforma utilizada pela instituição, somadas às demandas já existentes do trabalho do professor, que incluem a avaliação de aprendizagem, liderança de grupos de pesquisa, orientações de trabalhos acadêmicos, coordenação de projetos de extensão, dentre outras.

Nesse sentido, compreende-se que as dificuldades de boa parte dos participantes, citadas nesta pesquisa, estão 
relacionadas à sobrecarga de atividades, na medida em que, comprovadamente, o trabalho remoto docente impõe muito mais tempo e envolvimento, adaptação da nova rotina, além da dialógica atividade profissional e cotidiano familiar ${ }^{13,21}$. Dessa forma, as aulas ministradas no ambiente virtual tendem a ser mais cansativas e menos produtivas que aulas presenciais, em vista de todos os fatores mencionados, aos quais se acrescentam as demandas domésticas ${ }^{13}$.

Adaptar-se à nova modalidade de ensino em home office, integrando as atividades domésticas, o manuseio de TIC, as adequações do plano de ensino e as gravações das atividades são algumas adversidades sentidas pelos professores no decurso do ensino remoto, que podem desencadear síndrome do esgotamento profissional, estresse, ansiedade e depressão ${ }^{22}$.

No entanto, alguns relatos destacam efeitos positivos do ensino remoto decorrente da pandemia de Covid-19. Essa modalidade de ensino potencializou o desenvolvimento profissional dos professores, oportunizando aquisição de competências para novas formas de fazer o seu trabalho e a integração das TIC no processo pedagógico ${ }^{23}$. O regime especial de ensino remoto revelou a importância do desenvolvimento de novas maneiras de se relacionar com os alunos, colaboração com os colegas e a coordenação pedagógica, além da transferência de experiências de outros campos de atuação profissional para o ensino superior.

$\mathrm{Na}$ balança, entre as vantagens e desvantagens dessa forma de trabalho, ressaltam-se os seus reflexos negativos na qualidade de vida, principalmente das mulheres - maioria dos entrevistados neste estudo -, como o estresse emocional, as cobranças laborais e sociais e as dificuldades de cumprimento das múltiplas tarefas ${ }^{13,23}$.

O enfermeiro docente deve ser olhado como um profissional polivalente, com atividades diversas e de elevada complexidade, que se insere no contexto educacional e assistencial. Seu trabalho requer produção contínua, que, por vezes, repercute sobre os relacionamentos entre os pares. É ainda um trabalho que envolve ritmo intenso, demanda excessivamente horas de trabalho, inclusive quando se está "fora" do ambiente laboral, que seria um tempo dedicado ao cuidado de si. Assim, corroboram os achados de outro estudo, no qual aspectos inerentes à organização do trabalho e às dificuldades de relacionamento interpessoal se sobressaem como desafios para a humanização no trabalho do enfermeiro docente ${ }^{24}$.

Além disso, diante da vigência do semestre letivo ocorrer de forma remota, tem sido primordial o investimento pessoal na capacitação de uso de plataformas digitais, com as quais a grande maioria não possuía afinidade. Nesse sentido, o estudo destaca que existe familiaridade dos participantes em relação ao uso das TIC no ensino, mas de forma incipiente e sem explorar todo o seu potencial. Entretanto, o novo cenário levou-os a utilizar as novas aprendizagens e usos das tecnologias no processo de ensino. ${ }^{25}$

Nesse processo ensino-aprendizagem, o profissional pode ser atingido por essa problemática no que se refere às dificuldades encontradas pelos enfermeiros docentes diante do uso das TIC, muitas vezes desconhecida. A frustração docente vem do fato de não dominarem todas as perspectivas tecnológicas para efetivação do seu trabalho, bem como não terem domínio pleno dessa ferramenta, fazendo com que haja a ampliação da demanda ${ }^{26}$.

Estudo ${ }^{27}$ com professores de nível superior, no município do Rio de Janeiro, identificou aumento de $40 \%$ nas horas necessárias ao preparo de materiais para as atividades acadêmicas durante o ensino remoto. Observa-se que a elaboração de estratégias ativas de ensino-aprendizagem exige mudanças significativas na prática docente, mediante empenho de energia física, mental e emocional, aumentando, assim, a carga horária na preparação das aulas ${ }^{21}$.

O ensino remoto trouxe à tona a problemática da sobrecarga laboral dos docentes universitários. São atividades contínuas, que ultrapassam as jornadas de trabalho contratuais, sem pausas para descanso e disponibilidade a qualquer hora para atender às demandas da instituição e dos alunos. Essa situação foi agravada pela pandemia, tendo em vista a necessidade de aprendizagem para a utilização de TIC, além do apoio afetivoemocional aos alunos, que se encontram fragilizados e cheios de incertezas acerca do seu futuro ${ }^{28}$. Por exemplo, os participantes precisaram, além de se capacitar para atuarem com plataformas digitais, se preocupar se todos os seus alunos teriam condições de participar da atividade, seja devido a problemas de conexão com a internet ou barreiras financeiras.

Percebe-se, portanto, que o ensino remoto reverberou em desafios para o grupo de enfermeiros docentes, dentre os quais, a adaptação e a flexibilização relativas à nova forma de ensinar e à utilização das ferramentas tecnológicas, o que gera sentimentos de inseguranças e dúvidas ${ }^{29}$.

Pensando no contexto das relações de trabalho, os professores universitários ainda estão sujeitos ao sistema de trabalho sazonal especialmente em instituições privadas, onde a rotatividade é alta e as pressões físicas, cognitivas e mentais para cumprir metas potencializam o desgaste à saúde ${ }^{30}$. Nesse sentido, estudo $^{31} \mathrm{com}$ professores universitários da China identificou quadros de transtorno depressivo leve, transtorno afetivo bipolar, ansiedade generalizada, transtorno de adaptação e burnout, desencadeados ou agravados pela pandemia de Covid-19.

Dessa forma, torna-se importante garantir melhores condições de trabalho aos professores universitários para a realização do ensino remoto. Estudo ${ }^{32}$ com enfermeiros docentes de uma instituição rural nos Estados Unidos da América observou que aqueles professores que conseguiram enfrentar melhor os desafios e mudanças decorrentes da pandemia apresentaram melhor qualidade de vida.

Adicionalmente, os participantes deste estudo revelaram sentir-se sozinhos, amedrontados, tristes, angustiados e estressados, sendo esses efeitos atribuídos à sobrecarga laboral e a desmotivação para ministrar aulas no ambiente virtual, dados corroborados por outras pesquisas ${ }^{31,33}$.

Nessa mesma direção, o ensino remoto consolida a lógica de ensino bancário, no contexto atual caracterizado como 
"monólogos digitais". As relações entre professor e aluno durante as aulas virtuais são inexistentes, sem partilha e expressão de sentimentos e emoções, com ausência de qualquer tipo de troca de saberes e práticas ${ }^{33}$. Isso se evidenciou pelo frequente cenário: professores com câmera e áudio ativados durante as aulas, olhando para telas de computadores "vazias", sem contato, inclusive, visual com os alunos.

O fato de estarem em isolamento social pode ainda desencadear ou potencializar problemas agudos, como angústia, irritabilidade, insônia, alterações de humor, sintomatologia depressiva, medo, ansiedade, raiva e estresse, relacionados às restrições na rotina, dificuldades financeiras e problemas para estabelecer comunicação com outras pessoas ${ }^{34}$. De fato, deve-se pensar que esses trabalhadores não estão isentos aos efeitos danosos da pandemia de Covid-19 a que a população em geral está imersa.

Estudo ${ }^{35} \mathrm{com}$ brasileiros maiores de idade demonstrou que pessoas em isolamento social sentiam mais medo de contrair a infecção pelo Sars-CoV-2 e de sair de casa. Assim, experienciando o distanciamento social, esses professores requerem equilíbrio emocional e boas práticas para manter, também, bons níveis de saúde física, mental e financeira, bem como o restante da sociedade.

Os professores universitários reconhecem a necessidade do cuidado de si, mas o trabalho ocupa mais tempo do que almejavam, provocando impactos em sua qualidade de vida e hábitos ${ }^{36}$. Tal fato foi maximizado pela pandemia, considerando que os docentes têm sentido perda da vida privada. Essas situações contribuem para aumentar as queixas de sintomas físicos e psíquicos, como estresse, insônia, exaustão, dores no corpo, problemas vocais e danos emocionais, que eram comuns entre os professores universitários antes da pandemia ${ }^{22,37}$.

No cenário de pandemia e diante dos desafios relacionados ao distanciamento social, visando a continuidade das atividades acadêmicas em instituições universitárias, torna-se necessário refletir sobre os caminhos possíveis ao ensino superior, diante da nova realidade de trabalho dos professores universitários, além de buscar trilhas para a reconstrução da identidade profissional ${ }^{38}$.

Vale destacar, no entanto, que, no ensino de enfermagem, já se evidencia o uso de diversas TIC incorporadas às atividades presenciais, mas de forma complementar ${ }^{20}$. Contudo, as novas exigências decorrentes do cenário de pandemia, ao mesmo tempo em que podem provocar ressignificação da prática docente, com aquisição de novas competências a serem inseridas num contexto presencial futuro, têm gerado impactos negativos, sejam eles financeiros - decorrentes de maior jornada de trabalho sem compensação salarial - ou em termos de saúde - pela incompatibilidade da vida social e laboral, da sobrecarga laboral e da falta de habilidades para lidar com as TIC -, ocasionando frustração ${ }^{33}$.

\section{CONSIDERAÇÕES FINAIS E IMPLICAÇÕES PARA A PRÁTICA}

Os participantes desta pesquisa caracterizaram os efeitos do ensino remoto na vida pessoal e laboral e para sua saúde física e mental, como desafios a serem enfrentados. Desafios que se relacionaram à adequação de conteúdo e práticas pedagógicas ao ensino remoto, à rotina laboral e às atividades do cotidiano familiar. Também destacaram aquisição de novas competências profissionais, com uma integração maior das tecnologias digitais no processo ensino-aprendizagem, que pode contribuir significativamente à educação em enfermagem.

Os enfermeiros docentes mencionaram, no entanto, que algumas vezes se sentem tristes, sozinhos e angustiados diante da falta de uma relação mais próxima com os alunos e colegas de trabalho. Além disso, destacaram que o ensino remoto tem oferecido riscos de adoecimento associados à sobrecarga laboral, trabalho repetitivo e de aspectos físicos inerentes às plataformas digitais, como a luminosidade, acarretando danos à sua saúde física e emocional.

Este estudo apresenta, como limitações, o fato de o roteiro de entrevista não ter sido submetido a teste-piloto, justificado pelo reduzido quantitativo de enfermeiros docentes na instituição pesquisada; e, ainda, a não devolução das entrevistas aos participantes, tendo em vista a exaustão sentida por eles, pois estavam em período de adaptação ao uso das tecnologias digitais. Ademais, a submissão do instrumento de pesquisa a peritos na área poderia conferir maior qualidade metodológica ao estudo, sendo recomendada a pesquisas futuras.

Espera-se que esta pesquisa contribua para as discussões acerca da saúde dos enfermeiros docentes, uma temática ainda incipiente nas investigações na perspectiva do contexto de pandemia de Covid-19, porquanto se observou que os problemas decorrentes do ensino remoto - na verdade - são condições de longo tempo, intensificadas pelo momento contemporâneo de adaptação às novas modalidades de ensino, e que se caracterizam como obstáculos para a humanização no trabalho docente.

Dessarte, almeja-se que estratégias para a mitigação dos riscos de adoecimento desses profissionais - em particular, no decurso de acontecimentos inesperados, como a Covid-19 sejam elaboradas, considerando-se as exigências do trabalho docente reveladas neste estudo e em pesquisas congêneres.

\section{CONTRIBUIÇÕES DOS AUTORES}

Desenho do estudo. Anna Raquel Lima Araújo. Larisse Marques Costa Sousa. Rita Beatriz de Sousa Carvalho. Carolinne Kilcia Carvalho Sena Damasceno

Coleta ou produção dos dados. Anna Raquel Lima Araújo. Larisse Marques Costa Sousa. Rita Beatriz de Sousa Carvalho.

Análise de dados. Anna Raquel Lima Araújo. Larisse Marques Costa Sousa. Rita Beatriz de Sousa Carvalho. Adélia Dalva da Silva Oliveira. Fernanda Cláudia Miranda Amorim. Kayo Henrique Jardel Feitosa Sousa. Regina Célia Gollner Zeitoune. Carolinne Kilcia Carvalho Sena Damasceno

Interpretação dos resultados. Anna Raquel Lima Araújo. Larisse Marques Costa Sousa. Rita Beatriz de Sousa Carvalho. Adélia Dalva da Silva Oliveira. Fernanda Cláudia Miranda Amorim. Kayo Henrique Jardel Feitosa Sousa. Regina Célia Gollner Zeitoune. Carolinne Kilcia Carvalho Sena Damasceno 
Redação e revisão crítica do manuscrito. Anna Raquel Lima Araújo. Larisse Marques Costa Sousa. Rita Beatriz de Sousa Carvalho. Adélia Dalva da Silva Oliveira. Fernanda Cláudia Miranda Amorim. Kayo Henrique Jardel Feitosa Sousa. Regina Célia Gollner Zeitoune. Carolinne Kilcia Carvalho Sena Damasceno

Aprovação da versão final do artigo. Anna Raquel Lima Araújo. Larisse Marques Costa Sousa. Rita Beatriz de Sousa Carvalho. Adélia Dalva da Silva Oliveira. Fernanda Cláudia Miranda Amorim. Kayo Henrique Jardel Feitosa Sousa. Regina Célia Gollner Zeitoune. Carolinne Kilcia Carvalho Sena Damasceno

Responsabilidade por todos os aspectos do conteúdo e a integridade do artigo publicado. Anna Raquel Lima Araújo. Larisse Marques Costa Sousa. Rita Beatriz de Sousa Carvalho. Adélia Dalva da Silva Oliveira. Fernanda Cláudia Miranda Amorim. Kayo Henrique Jardel Feitosa Sousa. Regina Célia Gollner Zeitoune. Carolinne Kilcia Carvalho Sena Damasceno

\section{EDITOR ASSOCIADO}

Cristina Rosa Baixinho (D)

\section{EDITOR CIENTÍFICO}

Ivone Evangelista Cabral (D)

\section{REFERÊNCIAS}

1. World Health Organization. Coronavirus disease (COVID-19). Situation Report-142 [Internet]. 2020 [citado 2021 abr 29]. Disponível em: https:// apps.who.int/iris/handle/10665/332391?show=full

2. Morawska L, Milton DK. It is time to address airborne transmission of coronavirus disease 2019 (COVID-19). Clin Infect Dis. 2020;71(9):23113. http://dx.doi.org/10.1093/cid/ciaa939. PMid:32628269.

3. Chen W, Zhang N, Wei JJ, Yen HL, LiY. Short-range airborne route dominates exposure of respiratory infection during close contact. Build Environ. 2020;176:106859. http://dx.doi.org/10.1016/j.buildenv.2020.106859.

4. Silva LLS, Lima AFR, Polli DA, Razia PFS, Pavão LFA, Cavalcanti $\mathrm{MAFH}$ et al. Medidas de distanciamento social para o enfrentamento da COVID-19 no Brasil: caracterização e análise epidemiológica por estado. Cad Saude Publica. 2020;36(9):e00185020. http://dx.doi. org/10.1590/0102-311x00185020. PMid:32965378.

5. Candido DS, Claro IM, de Jesus JG, Souza WM, Moreira FRR, Dellicour $\mathrm{S}$ et al. Evolution and epidemic spread of SARS-CoV-2 in Brazil. Science. 2020 set 04;369(6508):1255-60. http://dx.doi.org/10.1126/science. abd2161. PMid:32703910.

6. Quaife M, van Zandvoort K, Gimma A, Shah K, McCreesh N, Prem $\mathrm{K}$ et al. The impact of COVID-19 control measures on social contacts and transmission in Kenyan informal settlements. BMC Med. 2020;18(1):316. http://dx.doi.org/10.1186/s12916-020-01779-4. PMid:33012285.

7. Trentini F, Guzzetta G, Galli M, Zardini A, Manenti F, Putoto G et al. Modeling the interplay between demography, social contact patterns, and SARS-CoV-2 transmission in the South West Shewa Zone of Oromia Region, Ethiopia. BMC Med. 2021;19(1):89. http://dx.doi.org/10.1186/ s12916-021-01967-w. PMid:33832497.

8. Davies NG, Barnard RC, Jarvis CI, Russell TW, Semple MG, Jit $M$ et al. Association of tiered restrictions and a second lockdown with COVID-19 deaths and hospital admissions in England: a modelling study. Lancet Infect Dis. 2021;21(4):482-92. http://dx.doi.org/10.1016/ S1473-3099(20)30984-1. PMid:33357518.

9. Portaria $\mathrm{n}$. 343, de 17 de março de 2020 (BR). Dispõe sobre a substituição das aulas presenciais por aulas em meios digitais enquanto durar a situação de pandemia do Novo Coronavírus - COVID-19. Diário Oficial da União, Brasília (DF), 18 mar 2020: Seção 1: 39.
10. Portaria n. -345 , de 19 de março de 2020 (BR). Altera a Portaria MEC n. ${ }^{\circ}$ 343, de 17 de março de 2020. Diário Oficial da União, Brasília (DF), 19 mar 2020: Seção 1: Extra.

11. Portaria $\mathrm{n} .{ }^{5} 44$, de 16 de junho de 2020 (BR). Dispõe sobre a substituição das aulas presenciais por aulas em meios digitais, enquanto durar a situação de pandemia do novo coronavírus - Covid-19, e revoga as Portarias MEC n. 343 , de 17 de março de 2020, n.ํ 345, de 19 de março de 2020, e n. 473 , de 12 de maio de 2020. Diário Oficial da União, Brasília (DF), 17 jun 2020: Seção 1: 62.

12. Lira ALBC, Adamy EK, Teixeira E, Silva FV. Nursing education: challenges and perspectives in times of the COVID-19 pandemic. Rev Bras Enferm. 2020;73(Suppl 2):e20200683. http://dx.doi.org/10.1590/0034-71672020-0683. PMid:33111782.

13. Souza KR, Santos GB, Rodrigues AMS, Felix EG, Gomes L, Rocha $\mathrm{GL}$ et al. Trabalho remoto, saúde docente e greve virtual em cenário de pandemia. Trab Educ Saúde. 2021;19:e00309141. http://dx.doi. org/10.1590/1981-7746-sol00309.

14. Minayo MCS. O desafio do conhecimento: pesquisa qualitativa em saúde. 8 ${ }^{\underline{a}}$ ed. São Paulo: Hucitec; 2011.

15. Leigh J, Vasilica C, Dron R, Gawthorpe D, Burns E, Kennedy S et al. Redefining undergraduate nurse teaching during the coronavirus pandemic: use of digital technologies. Br J Nurs. 2020;29(10):566-9. http://dx.doi.org/10.12968/bjon.2020.29.10.566. PMid:32463742.

16. Yeo SC, Lai CKY, Tan J, Gooley JJ. A targeted e-learning approach for keeping universities open during the COVID-19 pandemic while reducing student physical interactions. PLoS One. 2021;16(4):e0249839. http:// dx.doi.org/10.1371/journal.pone.0249839. PMid:33831082.

17. Gusso HL, Archer AB, Luiz FB, Sahão FT, Luca GG, Henklain MHO et al. Ensino superior em tempos de pandemia: diretrizes à gestão universitária Educ Soc. 2020;41:e238957. http://dx.doi.org/10.1590/es.238957.

18. Adedoyin OB, Soykan E. Covid-19 pandemic and online learning: the challenges and opportunities. Interact Learn Environ. 2020;1-13. http:// dx.doi.org/10.1080/10494820.2020.1813180.

19. Riegel F, Martini JG, Bresolin P, Mohallem AGC, Nes AAG. Developing critical thinking in the teaching of Nursing: a challenge in times of Covid-19 pandemic. Esc Anna Nery. 2021;25(spe):e20200476. http:// dx.doi.org/10.1590/2177-9465-ean-2020-0476.

20. Bezerra IMP. State of the art of nursing education and the challenges to use remote technologies in the time of coronavirus pandemic. $J$ Hum Growth Dev. 2020;30(1):141-7. http://dx.doi.org/10.7322/jhgd. v30.10087.

21. Saraiva K, Traversini C, Lockmannk A. Educação em tempos de COVID-19: ensino remoto e exaustão docente. Prax Educ (St Rosa). 2020;15:e2016289. http://dx.doi.org/10.5212/PraxEduc.v.15.16289.094.

22. Araújo FJ, Lima LS, Cidade PI, Nobre CB, Rolim ML No. Impact of Sars-Cov-2 and its reverberation in global higher education and mental health. Psychiatry Res. 2020;288:112977. http://dx.doi.org/10.1016/j. psychres.2020.112977. PMid:32302818.

23. Silva CM, Toriyama ATM, Claro HG, Borghi CA, Castro TR, Salvador PICA. COVID-19 pandemic, emergency remote teaching and Nursing Now: challenges for nursing education. Rev Gaúcha Enferm. 2021;42(esp):e20200248. http://dx.doi.org/10.1590/19831447.2021.202002487.

24. Castro MR, Sousa KHJF, Nascimento FPB, Tracera GMP, Santos KM, Zeitoune RCG. Challenges for humanization in the work of Nursing educators. Rev Gaúcha Enferm. 2020;41:e20190390. http://dx.doi. org/10.1590/1983-1447.2020.20190390. PMid:33237221.

25. Julião AL. Professores, tecnologias educativas e COVID-19: realidades e desafios em Angola. RAC: revista angolana de ciências. [Internet]. 2020 [citado 2021 abr 29];2(2):e020205. Disponível em: http://publicacoes. scientia.co.ao/ojs2/index.php/rac/article/view/105

26. Huang R, Tlili A, Chang TW, Zhang X, Nascimbeni F, Burgos D. Disrupted classes, undisrupted learning during COVID-19 outbreak in China: application of open educational practices and resources. Smart Learning Environments. 2020;7(1):19. http://dx.doi.org/10.1186/ s40561-020-00125-8.

27. Barbosa AM, Viegas MAS, Batista RLNFF. Aulas presenciais em tempos de pandemia: relatos de experiências de professores do nível 
superior sobre as aulas remotas. Rev Augustus. 2020;25(51):255-80. http://dx.doi.org/10.15202/1981896.2020v25n51p255.

28. Silveira A, Santos NO, Wilhelm LA, Soccol KLS, Tisott ZL, Prates LA. Estratégias e desafios do ensino remoto na enfermagem. Enferm foco. 2020;11(5):98-103. https://doi.org/10.21675/2357-707X.2020.v11. n5.4302.

29. Bao W. COVID -19 and online teaching in higher education: a case study of Peking University. Hum Behav Emerg Technol. 2020;2(2):113-5. http://dx.doi.org/10.1002/hbe2.191. PMid:32510042.

30. Gemelli CE, Closs LQ, Fraga AM. Multiformidade e pejotização: (re) configurações do trabalho docente no ensino superior privado sob o capitalismo flexível. REAd Rev Eletrôn Adm. 2020;26(2):409-38. http:// dx.doi.org/10.1590/1413-2311.289.101464.

31. Wang J, Wang Z. Strengths, weaknesses, opportunities and threats (swot) analysis of China's prevention and control strategy for the COVID-19 epidemic. Int J Environ Res Public Health. 2020;17(7):22-35. http:// dx.doi.org/10.3390/ijerph17072235. PMid:32225019.

32. Keener TA, Hall K, Wang K, Hulsey T, Piamjariyakul U. Relationship of quality of life, resilience, and associated factors among nursing faculty during COVID-19. Nurse Educ. 2021;46(1):17-22. http://dx.doi. org/10.1097/NNE.0000000000000926. PMid:32941307.
33. Santos HMR. Os desafios de educar através da Zoom em contexto de pandemia: investigando as experiências e perspectivas dos docentes portugueses. Prax Educ (St Rosa). 2020;15:e2015805. http://dx.doi. org/10.5212/PraxEduc.v.15.15805.091.

34. Brooks SK, Webster RK, Smith L, Woodland L, Wessely S, Greenberg $\mathrm{N}$ et al. The psychological impact of quarantine and how to reduce it: rapid review of the evidence. Lancet. 2020;395(10227):912-20. http:// dx.doi.org/10.1016/S0140-6736(20)30460-8. PMid:32112714.

35. Bezerra CB, Saintrain MVL, Braga DRA, Santos FS, Lima AOP, Brito EHS et al. Impacto psicossocial do isolamento durante pandemia de COVID-19 na população brasileira: análise transversal preliminar. Saude Soc.2020;29(4):e200412. http://dx.doi.org/10.1590/s0104-12902020200412.

36. Cecílio S, Reis BM. Trabalho docente na era digital e saúde de professores universitários. Educ Teor Prat. 2016;26(52):295-311. http:// dx.doi.org/10.18675/1981-8106.vol26.n52.p295-311.

37. Cortez PA, Souza MVR, Amaral LO, Silva LCA. A saúde docente no trabalho: apontamentos a partir da literatura recente. Cad Saude Colet. 2017;25(1):113-22. http://dx.doi.org/10.1590/1414-462x201700010001.

38. Camacho ACLF, Joaquim FL, Menezes HF, Sant'Anna RM. Tutoring in distance education in times of COVID-19: relevant guidelines. Res Soc Dev. 2020;9(5):e30953151. http://dx.doi.org/10.33448/rsd-v9i5.3151.

\footnotetext{
artigo extraído do Trabalho de Conclusão de Curso de Bacharelado em Enfermagem: Regime especial de aprendizagem remota na perspectiva do docente de graduação, sob orientação da professora Carolinne Kilcia Carvalho Sena Damasceno, apresentado ao Centro Universitário Uninovafapi, em 8 de dezembro de 2020.
} 